\title{
Long term changes in the visual fields of patients with temporal lobe epilepsy using vigabatrin
}

\author{
P Hardus, W M Verduin, G Postma, J S Stilma, T T J M Berendschot, C W M van Veelen
}

\begin{abstract}
Aim-To study the long term changes in the concentric contraction of the visual field in patients with temporal lobe epilepsy on vigabatrin medication.

Methods-Repeated Goldmann visual field examinations were compared in 27 patients with drug resistant temporal lobe epilepsy and concentric contraction of the visual field. Two groups were studied: 16 patients who had already stopped vigabatrin medication before surgery and 11 patients who continued vigabatrin medication.

Results-Concentric contraction of the visual field did not change in 16 patients who stopped vigabatrin before the first examination; there was slight but significant progress in visual field loss in 11 patients who continued the use of vigabatrin.

Conclusion-Long term follow up of concentric contraction in this selected group of patients indicates that vigabatrin associated visual field loss is not reversible and that progression is possible when vigabatrin is continued.

(Br f Ophthalmol 2000;84:788-790)
\end{abstract}

Department of Ophthalmology, Academic Hospital Groningen,

Netherlands

P Hardus

Department of Ophthalmology, University Medical

Centre Utrecht, Netherlands

W M Verduin

J S Stilma

T T J M Berendschot

Department of

Functional

Neurosurgery,

University Medical

Centre Utrecht,

Netherlands

G Postma

C W M van Veelen

Correspondence to:

J S Stilma, Department of

Ophthalmology, University

Medical Centre/E03.136, PO

Box 85.500, NL-3508 GA

Utrecht, Netherlands

J.Stilma@oogh.azu.nl

Accepted for publication 8 February 2000
The association of vigabatrin medication with concentric contraction of the visual field has been established in recent publications..$^{1-12}$ In a previous study we found a statistical relation between concentric contraction and the use of vigabatrin. The prevalence of concentric contraction was $17 \%$ (20 out of 118 patients using vigabatrin). ${ }^{13}$ We wanted to know whether concentric contraction of the visual field in epilepsy patients is reversible when vigabatrin is discontinued or progressive when vigabatrin is continued.

\section{Patients and methods}

PATIENTS

The University Medical Centre Utrecht acts as the only referral centre for neurosurgical treatment of drug resistant epilepsy in the Netherlands. Visual field examination is a standard part of the preoperative and postoperative evaluation since July 1991. Concentric contraction was found in 28 out of 143 patients selected for neurosurgical treatment and using vigabatrin in the past or present. All patients with concentric contraction of the visual field before surgery were called for follow up examination after 6 weeks and again at least 4 months after surgery.

Visual field examinations were performed with the standard Goldmann perimeter (Haag
Streit, Switzerland) as described before ${ }^{13}$ by the same person (WV) who has 25 years' experience in perimetry.

\section{GRADING OF VISUAL FIELD LOSS}

Absolute loss of visual field was defined as the inability to see the largest and brightest object of the Goldmann perimeter (V/4). The extent of concentric contraction was quantified with the Esterman grid ${ }^{14}{ }^{15}$ because this method is internationally accepted for the evaluation of impairment of vision.

ANALYSIS

Surgical treatment of temporal lobe epilepsy may be complicated by more or less extensive loss of the homonymous upper quadrant of the visual field. In such cases, only the Esterman scores for the remaining three quadrants were compared. Further, a disadvantage of the Esterman grid is that the dots are not equally distributed over the four quadrants (superior temporal 19, inferior temporal 40, superior nasal 11, and inferior nasal 27). Since the quadrants omitted differed between patients (related to right or left side resection) comparison of Esterman scores is impossible. Therefore, for each quadrant we calculated the percentage loss, by dividing the loss in Esterman dots by the maximum number for that particular quadrant. Finally, we obtained percentage losses per eye, by averaging over the quadrants not affected by surgery.

Ophthalmological examination was performed on all patients with visual field abnormalities. This examination consisted minimally of visual acuity, biomicroscopy, and ophthalmoscopy after pupil dilatation.

\section{Results}

PATIENTS

One patient underwent hemispherectomy and was excluded because of severe abnormalities of the visual field. The patients were divided into two groups: group I, 16 patients who had stopped vigabatrin medication before surgery and the first visual field examination and group II, 11 patients who continued the use of vigabatrin after surgery. In no case was medication added after surgery. On the contrary, most patients needed less medication because of the effect of surgery. None of the patients reported changes in the visual field spontaneously.

VISUAL FIELD EXAMINATION

All patients were available for follow up examinations. The concentric contraction found varied between 10 and 30 degrees. 
Table 1 Loss of Esterman scores in 27 patients using vigabatrin

\begin{tabular}{|c|c|c|c|c|c|c|c|c|c|c|c|c|c|c|c|c|c|c|}
\hline \multirow[b]{4}{*}{$I D$} & \multirow{4}{*}{$\begin{array}{l}\text { Follow } \\
\text { up time } \\
\text { (months) }\end{array}$} & \multirow{4}{*}{$\begin{array}{l}\text { Using } \\
\text { vigabatrin } \\
\text { after } \\
\text { surgery }\end{array}$} & \multicolumn{8}{|c|}{ Right eye } & \multicolumn{8}{|c|}{ Left eye } \\
\hline & & & \multicolumn{4}{|c|}{ Measurement 1} & \multicolumn{4}{|c|}{ Measurement 2} & \multicolumn{4}{|c|}{ Measurement 1} & \multicolumn{4}{|c|}{ Measurement 2} \\
\hline & & & \multicolumn{2}{|c|}{ Temporal } & \multicolumn{2}{|c|}{ Nasal } & \multicolumn{2}{|c|}{ Temporal } & \multicolumn{2}{|c|}{ Nasal } & \multicolumn{2}{|c|}{ Temporal } & \multicolumn{2}{|c|}{ Nasal } & \multicolumn{2}{|c|}{ Temporal } & \multicolumn{2}{|c|}{ Nasal } \\
\hline & & & $S$ & $I$ & $S$ & $I$ & $S$ & $I$ & $S$ & $I$ & $S$ & $I$ & $S$ & $I$ & $S$ & $I$ & $S$ & $I$ \\
\hline 1 & 8.1 & no & 2 & 7 & 1 & 3 & 2 & 5 & 1 & 2 & 2 & 5 & 4 & 8 & 3 & 2 & 2 & 8 \\
\hline 2 & 6.0 & no & & 6 & 2 & 3 & & 7 & 2 & 3 & 4 & 7 & & 5 & 3 & 8 & & 5 \\
\hline 3 & 7.2 & no & & 0 & 4 & 4 & & 3 & 3 & 3 & 0 & 0 & & 5 & 0 & 0 & & 5 \\
\hline 4 & 11.2 & no & & 3 & 1 & 1 & & 3 & 1 & 1 & 0 & 2 & & 1 & 0 & 1 & & 1 \\
\hline 5 & 26.7 & no & & 0 & 3 & 5 & & 2 & 3 & 6 & 0 & 1 & & 6 & 0 & 2 & & 7 \\
\hline 6 & 35.2 & no & & 6 & 4 & 4 & & 7 & 3 & 4 & 2 & 8 & & 6 & 2 & 7 & & 7 \\
\hline 7 & 26.4 & no & & 10 & 4 & 6 & & 13 & 4 & 6 & 5 & 12 & & 7 & 5 & 12 & & 6 \\
\hline 8 & 11.3 & no & & 7 & 4 & 7 & & 7 & 5 & 7 & 3 & 7 & & 6 & 3 & 7 & & 7 \\
\hline 9 & 20.3 & no & & 5 & 3 & 5 & & 5 & 2 & 3 & 2 & 6 & & 6 & 2 & 5 & & 5 \\
\hline 10 & 24.9 & no & & 7 & 3 & 6 & & 8 & 2 & 5 & 2 & 4 & & 6 & 2 & 4 & & 6 \\
\hline 11 & 31.8 & no & & 7 & 3 & 6 & & 8 & 3 & 6 & 3 & 6 & & 6 & 2 & 7 & & 6 \\
\hline 12 & 52.1 & no & 2 & 8 & 5 & 7 & 2 & 7 & 5 & 7 & 2 & 9 & 6 & 7 & 2 & 9 & 6 & 8 \\
\hline 13 & 28.2 & no & 3 & 10 & & 9 & 4 & 9 & & 9 & & 12 & 6 & 7 & & 9 & 5 & 7 \\
\hline 14 & 35.2 & no & 0 & 2 & & 2 & 0 & 1 & & 2 & & 0 & 1 & 0 & & 0 & 0 & 1 \\
\hline 15 & 62.4 & no & 0 & 0 & 2 & 2 & 0 & 0 & 3 & 0 & 0 & 0 & 2 & 2 & 0 & 0 & 2 & 5 \\
\hline 16 & 24.7 & no & 6 & 15 & & 14 & 6 & 17 & & 14 & & 16 & 6 & 11 & & 16 & 6 & 12 \\
\hline 17 & 13.4 & Yes & 1 & 5 & 3 & 6 & 1 & 3 & 3 & 5 & 1 & 5 & 3 & 6 & 1 & 3 & 2 & 6 \\
\hline 18 & 61.4 & Yes & 2 & 7 & 3 & 7 & 5 & 13 & 4 & 7 & 3 & 6 & 2 & 4 & 5 & 13 & 4 & 6 \\
\hline 19 & 30.5 & Yes & 6 & 13 & 3 & 7 & 6 & 14 & 3 & 7 & 5 & 14 & 4 & 7 & 6 & 16 & 4 & 7 \\
\hline 20 & 35.0 & Yes & & 0 & 1 & 0 & & 0 & 1 & 0 & 0 & 1 & & 0 & 0 & 0 & & 0 \\
\hline 21 & 40.0 & Yes & & 11 & 3 & 6 & & 13 & 3 & 8 & 5 & 12 & & 9 & 5 & 14 & & 9 \\
\hline 22 & 41.1 & Yes & & 7 & 2 & 5 & & 13 & 2 & 7 & 2 & 7 & & 3 & 3 & 11 & & 5 \\
\hline 23 & 26.8 & Yes & & 13 & 3 & 7 & & 16 & 4 & 7 & 2 & 7 & & 8 & 4 & 16 & & 13 \\
\hline 24 & 48.8 & Yes & 1 & 4 & & 5 & 2 & 6 & & 5 & & 1 & 2 & 3 & & 4 & 2 & 1 \\
\hline 25 & 28.7 & Yes & 0 & 0 & 2 & 4 & 2 & 5 & 2 & 5 & 0 & 0 & 3 & 4 & 3 & 5 & 3 & 4 \\
\hline 26 & 35.0 & Yes & 2 & 7 & 2 & 5 & 2 & 7 & 3 & 7 & 2 & 6 & 2 & 2 & 3 & 6 & 2 & 4 \\
\hline 27 & 24.9 & Yes & 6 & 14 & & 8 & 6 & 14 & & 7 & & 14 & 6 & 9 & & 14 & 6 & 10 \\
\hline
\end{tabular}

Measurement 1 = first visual field examination before surgery.

Measurement 2 = last visual field made after surgery.

Follow up is the time in months between the first and last examination.

Blank $=$ not counted because of visual field loss related to surgery.

$\mathrm{S}=$ superior; $\mathrm{I}=$ inferior.

GRADING OF THE VISUAL FIELD LOSS

In no cases was there a change between the concentric contraction before surgery and 6 weeks after surgery, except for the superimposed loss in the superior homonymous quadrant resulting from the surgery.

ANALYSIS

Table 1 shows the loss in Esterman scores per quadrant for all the relevant quadrants and the follow up time in months. From these data the percentages of loss were calculated, which are summarised in Table 2. Because of the rather low numbers, it is hard to judge if our data are normally distributed or not. Using the nonparametric Wilcoxon signed ranks test we found no difference between the first and last measurements in group I (for right eyes difference $=-0.005$, range $(-0.05,0.03), p=0.72$; or left eyes difference $=-0.004$, range $(-0.05$, $0.054), p=0.68)$. This suggests that the visual field loss in this group is neither reversible nor progressive. In group II, 11 patients who continued vigabatrin medication, we found a small but significant decrease (for right eyes difference $=0.035$, range $(-0.02,0.09)$, $\mathrm{p}=0.020$ and for left eyes difference $=0.042$, range $(-0.03,0.17), p=0.024)$. When the same Wilcoxon signed rank test was applied to the inferior quadrants only we obtained a similar outcome.

There was no difference in the first measurement between the two groups (Mann-Whitney $\mathrm{U}$ test, $\mathrm{p}=0.93$ and $\mathrm{p}=0.94$ for right and left eye respectively). Also the time between the first and last measurements, 2.1 years (SD 1.3) and 2.9 years (1.1) for groups I and II respectively, was not significant (Mann-Whitney U test, $\mathrm{p}=0.07)$.

The two eyes are not independent. Therefore, we analysed them separately. To take their possible dependence into account we also applied a statistical general linear model (GLM), repeated measurement analyses on MP density with both time and eye as within subject factor. Here also, this results in no difference between the first and second measurements in group I $(\mathrm{p}=0.30)$ and a significant difference in group II $(p=0.019)$. In Figure 1, the comparison of first and second measurements for all 11 patients who continued the use of vigabatrin is shown graphically.

Table 2 Long term changes in the visual field as percentage loss in groups I and II

\begin{tabular}{|c|c|c|c|c|c|c|}
\hline \multirow{2}{*}{$\begin{array}{l}\text { Using vigabatrin after } \\
\text { surgery }\end{array}$} & \multicolumn{3}{|l|}{ Right eye } & \multicolumn{3}{|l|}{ Left eye } \\
\hline & Measurement 1 & Measurement 2 & Difference & Measurement 1 & Measurement 2 & Difference \\
\hline No, group I $(\mathrm{N}=16)$ & $17.3 \%$ & $16.9 \%$ & $0.4 \% \mathrm{p}=0.46$ & $17.7 \%$ & $17.3 \%$ & $0.5 \% \mathrm{p}=0.47$ \\
\hline Yes, group II $(\mathrm{N}=11)$ & $17.7 \%$ & $21.8 \%$ & $4.2 \% \mathrm{p}=0.043$ & $17.6 \%$ & $21.2 \%$ & $3.5 \% p=0.016$ \\
\hline
\end{tabular}

Measurement 1 = first visual field examination before surgery.

Measurement $2=$ last visual field after surgery. 


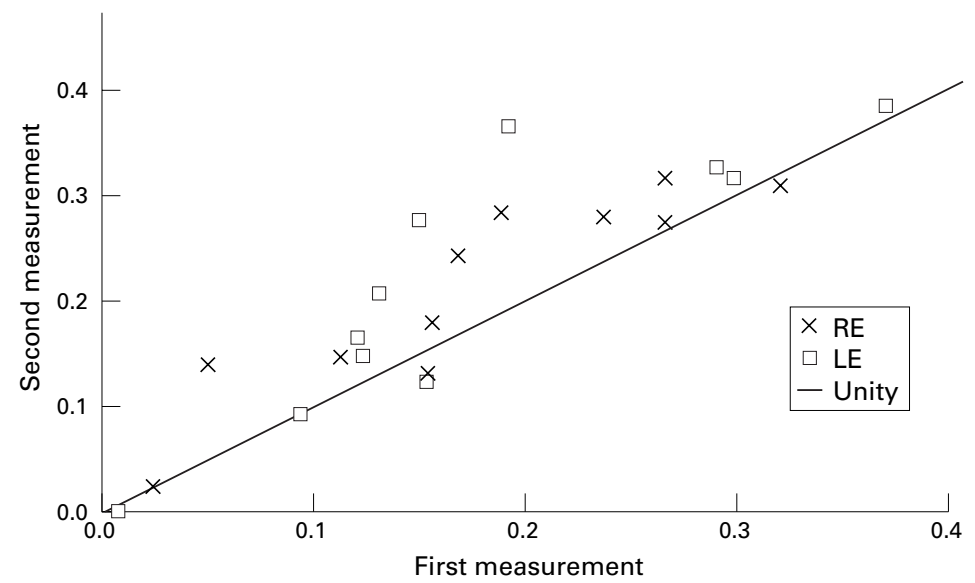

Figure 1 Comparison of loss of Esterman scores at the first and second measurements for all 11 patients that continued the use of vigabatrin. $X$ and $Y$ axes represent change ( $1=100 \%$ change). The solid line represents no change.

Ophthalmological examination did not reveal any abnormalities that could explain the concentric contraction of the visual field.

\section{Discussion}

To date there are few systematic reports on the potential reversibility or progression of the visual field loss in patients with epilepsy using vigabatrin. Eke et $a l^{1}$ did not observe improvement in three patients. Wilson and Brodie ${ }^{4}$ described one patient without improvement. In one patient described by Wong et $a l^{3}$ the visual field remained stable with half the dosage of vigabatrin for 4 years. Harding ${ }^{16}$ noted improvement in some cases but gives no details. Krauss et al studied 38 patients using vigabatrin and did not comment on visual field changes in three patients with visual field defects. Daneshvar et $a l^{10}$ reported recently on 12 patients with visual field contraction where no improvement was noted after withdrawal of vigabatrin. Lawden et $a l^{11}$ found that nine out of 12 patients with visual field loss who stopped vigabatrin did not improve, and three showed modest improvement. One of two patients who continued vigabatrin showed possible progression of field loss. Versino and Veggiotti ${ }^{17}$ reported a 10 year old girl with severe concentric contraction improving after stopping vigabatrin medication. Her visual field defect, however, showed a clover leaf configuration as is often seen in functional visual field defects. Wild et al ${ }^{12}$ studied 42 patients with vigabatrin attributed visual field loss and report under the discussion that "no evidence was available to indicate progressive deterioration in the visual field loss with continued therapy nor any evidence to suggest a recovery when vigabatrin was discontinued". They used four categories of visual field loss. Our study gives statistical evidence that progression of concentric contraction of the visual field does occur within a mean follow up of more than 2 years when vigabatrin medication is continued and that concentric contraction does not change or improve in patients who stopped vigabatrin medication. We realise that visual field examination has its limitations. ${ }^{18-20}$ The findings of visual field loss were, however, supported by the cooperation of all patients in a consecutive series and by the consistency of the defects that were found before and after surgery in both eyes. The present study was not focused on the pathogenesis of concentric contraction. Krauss et $a l^{7}$ and Daneshvar et $a l^{10}$ suggest that the toxic process lies in the inner retina. More pathophysiological studies are required before we understand the interaction of vigabatrin and the retina.

In the meantime we recommend visual field examination, including the far periphery, in patients with epilepsy requiring vigabatrin medication. If visual defects are found, the benefit of vigabatrin medication should be weighed against the visual field findings.

Conflict of interest: none.

1 Eke T, Talbot JF, Lawden MC. Severe persistent visual field constriction associated with vigabatrin. BMF 1997;314:180-1.

2 Blackwell N, Hayllar J, Kelly G. Severe persistent visual field constrictions associated with vigabatrin. BMF 1997;314: 1994.

3 Wong IC, Mawer GE, Sander JW. Severe persistent visual field constrictions associated with vigabatrin. BMF 1997; 314:1693-4.

4 Wilson EA, Brodie MJ. Severe persistent persistent visual field constrictions associated with vigabatrin. BMF 1997; 314:1993.

5 Mackenzie R, Klistorner A. Asymptomatic as well as symptomatic defects occur with vigabatrin. BMF 1997;316:233.

6 Kraemer G, Scollo-Lavizarri G, Jallon P, et al. Vigabatrin Kraemer G, Scollo-Lavizarri G, Jallon P, et al. Vigabatrin
associated bilateral concentric visual field defects in four associated bilateral concentric visual field

patients. Epilepsia 1997;38 (suppl 8): 179 .
7 Krauss GL, Johnson MA, Miller NR. Vigabatrin associated retinal cone system dysfunction. Neurology 1998;50:614-8.

8 Harding G, Wild J, Robertson K, et al. Electrooculography, ERGs, multifocal ERGs and VEPs in epileptic patients showing visual field disorders. Electroenceph Clin Neurophysiol 1997;103:96 (P13-14).

9 Rao GP, Ah Fat F, Kyle D, et al. Study is needed of visual field associated with any long term antiepileptic drug. BMF 1998;317:206

10 Daneshvar H, Racette L, Coupland SG, et al. Symptomatic and asymptomatic visual loss in patients taking vigabatrin. Ophthalmology 1999;106:1792-11.

11 Lawden MC, Eke T, Degg C, et al. Visual field defects associated with vigabatrin therapy. $\mathcal{F}$ Neurol Neurosurg Psychiatry 1999;67:716-22.

try 1999;67:716-22.
12 Wild JM, Martinez C, Reinshagen G, et al. Characteristics of a unique visual field defect attributed to vigabatrin. Epilepsia 1999;40:1784-94.

13 Hardus P, Verduin WM, Postma G, et al. Concentric contraction of the visual field in patients with temporal lobe epilepsy and its association with the use of vigabatrin. Epilepsia (in press).

14 Esterman B. Grids for functional scoring of visual fields. Doc Ophthal Proc Series Vol 26. Greve EL, Verriest G, eds.

15 American Medical Association. Guides to the evaluation of permanent impairment. 8/213. 4th ed. San Francisco: AMA, 1993.

16 Harding GFA. Severe persistent visual field constriction associated with vigabatrin. BMF 1998;316:322.

17 Versino M, Veggiotti P. Reversibility of vigabatrin-induced visual-field defect. Lancet 1999;354:486.

18 Stewart JGF. Automated perimetry and malingerers. Stewart JGF. Automated perin
Ophthalmology 1995;102:27-32.

19 Thompson JC, Kosmorsky GS, Ellis BD. Fields of dreamers and dreamed-up fields. Ophthalmology 1996;103:117-25.

20 Trauzettel-Klosinski S. Untersuchungsstrategien bei Simulation und funktionellen Sehstörungen. Klin Monatsbl Augenheilkd 1997;211:73-83. 